Research Article

\title{
Experimental and Numerical Analysis of Soil Cracking Characteristics under Evaporation
}

\author{
Di Feng $\mathbb{D}^{1,2}{ }^{1,2}$ Jiakun Gong, ${ }^{3}$ Xiaodong $\mathrm{Ni}\left(\mathbb{D},{ }^{1,2}\right.$ and Jie Ren ${ }^{3}$ \\ ${ }^{1}$ Key Laboratory of Ministry of Education for Geomechanics and Embankment Engineering, Hohai University, \\ Nanjing 210098, China \\ ${ }^{2}$ College of Civil and Transportation Engineering, Hohai University, Nanjing 210098, China \\ ${ }^{3}$ College of Mechanics and Materials, Hohai University, Nanjing 210098, China \\ Correspondence should be addressed to Di Feng; fengdi@hhu.edu.cn
}

Received 18 October 2021; Accepted 1 November 2021; Published 13 November 2021

Academic Editor: Gan Feng

Copyright (c) 2021 Di Feng et al. This is an open access article distributed under the Creative Commons Attribution License, which permits unrestricted use, distribution, and reproduction in any medium, provided the original work is properly cited.

\begin{abstract}
There are numerous cracks on soil surface in nature. These cracks are mainly formed by the continuous water loss and shrinkage of soil under evaporation. Cracks have an important effect on the properties of soil. The analysis of soil moisture movement and cracking characteristics under evaporation is of great significance to the engineering construction in the cracked soil area. In this work, an experimental study was conducted to investigate the development of soil cracks. Crack geometrical parameters were acquired at various developmental stages. According to this, the crack evolution characteristic was described qualitatively. The law of soil water movement was analyzed through the numerical simulation of evaporation effect on cracked soil. The relationship between soil moisture content and crack width was revealed, and the dynamic prediction of crack development under evaporation was realized. The results show that the development and evaporation process of soil cracks can be divided into three distinct stages, and the longer the stable evaporation time, the greater the development of cracks.
\end{abstract}

\section{Introduction}

Cracks prevail in natural soil grounds in the background of global warming and frequent drought flood disaster. The cracks are mainly formed by the continuous water loss and shrinkage of soil under evaporation. The existence of cracks would cause important effect on soil properties. The cracks would not only reduce the soil strength [1], but also provide preferential pathways for fluid flow and increase water infiltration or contaminant solute transport into soils $[2,3]$. Thus, the analysis of soil moisture movement and cracking characteristics under evaporation is of great significance to the engineering construction in the cracked soil area.

As the most important reason for the formation of soil cracks, the climate acts on soil as the engine, and the atmosphere provides state change of soil with solar radiation and rainfall infiltration ones. Evaporation links the soil and the atmosphere. Under the influence of climate, soil evaporates and shrinks continuously, which forms cracks. Many scholars studied the development rules of soil cracks in simulated climate through lab experiment. In order to investigate the desiccation cracks of clay liner in refuse landfill, Miller et al. [4] designed an experimental facility which can control climate factors such as temperature, rainfall, and wind speed and studied the development rules of cracks. Tang et al. [5-7] carried out a series of drying tests to study the dry shrinkage cracking property of swelled ground under different temperature. In the process of drying, the change of moisture content and the evolution of surface cracks were monitored in real time. The results showed that the critical moisture content during cracking was affected by temperature significantly. Liu et al. [8] adopted large-size compacted expansive soil samples to conduct crack development tests under various environmental humidity and temperature and discussed the influence of environmental humidity and temperature on the crack development law of expansive soil. The soil is prone to shrinkage and cracking under evaporation. Knowledge of the coupled behavior of cracking 
and moisture-heat evolution is helpful for better understanding the mechanical performance of soil under evaporation. Wu et al. [9] conducted an evaporation experiment for clayey soil specimen. The fully coupled behavior of shrinkage, cracking, and moisture-heat evolution of the clay under evaporation was investigated.

In order to master the essence of development of crack, the mechanism of development of crack must be understood first. Many scholars carried out relevant research and reached some achievements. Lee et al. [10] proposed a finite element model of the crack development of brittle soil based on linear crack mechanics. The model calculated the stress under given tensile load at different dots around preexisting cracks, and the direction of the maximum stress was the one of crack development. For cohesive soil affected by drying and shrinkage function, Bronswijk [11] found the transformation relationship between the vertical settlement of soil and the width and 3D volume change of cracks. However, this model cannot be used to calculate crack spacing under given soil and boundary conditions. Morris et al. [12] analyzed the theoretical relationship between crack depth, soil properties, and given matrix suction distribution and proposed three methods for predicting soil crack depth. Konrad and Ayad [13, 14] developed a theoretical model of soil cracking based on the field tests, the principles of elasticity theory, and the crack mechanics and analyzed the relationship between the tensile strength, Poisson ratio, and other factors of soil and the development depth of cracks. Based on the theory of temperature stress and elasticity, Wu et al. [15] established a theoretical model for calculating the swelling and contraction deformation of soil by using moisture content changes. The mechanism of crack generation is revealed, and the critical wetting criterion for initial cracks of expansive soil is promoted.

At present, the research on the development process of soil cracks generally focuses on the description and influence of soil cracks at a certain moment, while the development process of cracks should be a dynamic process affected by climate conditions. The dynamic development law of soil cracks needs to be further investigated. It is necessary to establish a long-term dynamic prediction and tracking method for the development of soil cracks under evaporation. The objectives of this study are to (i) quantitatively describe the cracking characteristics of soil, (ii) analyze the soil water transport under evaporation, and (iii) establish a dynamic prediction method for crack development.

\section{Experimental Study on the Development of Soil Surface Cracks}

In this experiment, a soil sample was compounded under laboratory conditions, and cracks would be generated in this soil sample with suitable climate conditions. During the evaporation process, the development of cracks could be observed in the soil sample.

2.1. Materials. The soil sample taken from the Huangshan Slope was packed into a rectangular box and in an undersaturated state initially. Typical geotechnical properties of the soil, including dry unit weight, specific gravity, liquid limit, plastic limit, and expansive index [2], are given in Table 1 . The soil is classified as silty clay with medium expansivity.

2.2. Experimental Setup. To study the development of soil crack under the effect of evaporation and the influence of climate on the development rule, an experimental apparatus was designed to observe the soil crack developing process. The experimental setup consists of a rectangular box with size of $1.0 \mathrm{~m} \times 1.0 \mathrm{~m} \times 0.5 \mathrm{~m}$ (as shown in Figure 1), which was made up of glass sheet. In order to reduce the boundary effect, the sides of the box were protected by plastic plate.

An open-area site without any obstructions was chosen as the test site to make soil sample completely exposed in natural conditions. In case of rain or inclement weather, the box was covered with a piece of glass sheet to prevent the increase of moisture. Once the cracks formed, the ruler was placed on the soil sample, and the breadth of the area in which the cracks were intensive was measured. The apparatus also includes an electronic balance, a digital camera, a ruler, a drying oven, and a temperature and humidity recorder.

2.3. Testing Procedures. The development of cracks in the soil sample during the evaporation process in nature condition was monitored. The entire experiment lasted about 20 days until the cracks that were observable with the naked eye became stable. In this process, the intermediate region in which the crack development was more obvious was selected to shoot. A ruler was placed aside as reference; meanwhile, the meteorological data such as temperature and humidity was recorded. The procedure is described as follows:

(1) Prepare test equipment and test material. Place soil sample in the glass box. Sign the region of $20 \mathrm{~cm} \times 20 \mathrm{~cm}$ with white line.

(2) Examine the cracks every 2 hours in the early developing period. Once the cracks appear, the sample is photographed from top at a fixed height. The meteorological data of the day is recorded by temperature and humidity measuring device and anemometer. The moisture content is measured through moisture content test with multiple soil samples that are taken from the site next to the observation area.

(3) The observation interval can be appropriately extended as the cracks become mature, which is indicated by the slow development of the width and length of cracks. In case of rain, the glass holder is covered with an organic glass plate. The experiment continues until the moisture content and the crack parameter change nonsignificantly. The development feature of cracks in vertical direction can be observed by disconnecting the plastic plate around the glass holder. The crack-surface morphology is observed by cutting the sample. 
TABLE 1: Properties of the soil in the laboratory crack development test [2].

\begin{tabular}{lc}
\hline Soil property & Values \\
\hline Dry unit weight of soil $\left(\mathrm{kN} / \mathrm{m}^{3}\right)$ & 16.9 \\
Specific gravity of soil particles & 2.71 \\
Liquid limit (\%) & 49.3 \\
Plastic limit (\%) & 26.8 \\
Expansive index & 53 \\
\hline
\end{tabular}



FIgURE 1: Experimental setup.

(4) The geometrical parameters of cracks were obtained by image-processing techniques.

(5) Analyze the influence of climate conditions and moisture content on sample cracking at each stage.

2.4. Developing Process of Cracks in Natural Conditions. Representative pictures of cracks at different development stages are shown in Figure 2. Initially, the sample clung to the glass box wall, with no shrink. The sample began to shrink integrally and separate from the wall as the moisture content decreased, in which stage a significant shrinkage appeared at the beginning as the moisture content decreased while the shrinkage had no change in the later period. In this stage, in spite of significant decrease of moisture content, only global shrinkage existed in the sample without cracking. As the moisture evaporated further, a small crack appeared on the surface, which would extend along its direction until being obstructed by other cracks or the margin of the sample. Then, as the moisture content further decreased, the crack propagated longer and faster until several main cracks emerged steadily. The development of cracks ran through the whole sample surface, and a complex crack network formed eventually.

2.5. Analysis of the Geometric Parameters of the Cracks. In order to quantitatively study the development law of soil cracks, a digital imaging method [16] can be used to extract the crack parameters at various stages, including the number, length, width, and ratio of cracks. Crack ratio is defined as the ratio of the crack area to the total surface area of soil. A photograph of the cracks can be imported into the AutoCAD software and scaled to its full size based on the reference scales. The crack is treated as a straight line. AutoCAD then provides the information of the straight line. The geometric parameters of soil cracks are given in Table 2.

As shown in Figure 2 and Table 2, the initial formative period continued 2 3 days, in which the cracks decentralized and separated from each other; they were generated firstly in the form of a single crack, and then the quantity, length, and width of cracks increased slowly. Then, a primary crack across the observation area appeared, with a lot of secondary cracks derived and developed quickly. This period was named as the fast development period. The quantity of cracks reached 248 on the seventh day, which marked the formation of the shape of the crack network. The shrinkage of some microcracks due to the effect of the humidity outside led to the possible increase of the volume of the sample, which caused the fluctuation of the quantity of the cracks. The reflection of crack development was not only the increase in the quantity but also the increase in the length and the width. On the $12^{\text {th }}$ day, the quantity decreased more significantly compared to the day before, which was mainly caused by the compression or closure of some secondary cracks due to the rapid growth of the primary crack. 18 days later, the quantity, length, and width of the cracks remained steady till the end of the development period, continuing $4 \sim 15$ days. In the stable period, the total length of the cracks was about $1966 \mathrm{~mm}$, and the width of the primary crack was about $22 \mathrm{~mm}$, with average of $1.77 \mathrm{~mm}$.

Figure 3 shows stages divided by the crack ratio in the whole development process of the cracks. Due to the inevitable operation error, some area might show lower moisture rate, where the critical moisture rate is reached first under the same evaporation conditions, leading to the early formation of cracks with low cracking rate. With the soil cracking, to further increase the boundary of evaporation, the crack width and length continued developing; in the meantime, the primary crack began to develop secondary cracks that were less than the primary crack in the width and length. From the energy perspective, the development of cracks released most of the energy. Moreover, the secondary cracks generally existed in the inside polygon, where the soil was cut into pieces by the primary crack and squeezed to some extent, resulting in the limitation of the lateral deformation. This stage was defined as the development period, in which the cracking rate increased quickly from 0.0049 to 0.1398 . The last stage was the stable period of crack morphology, indicated by the crack network being basically stable. On the one hand, the length of primary and secondary cracks and the quantity of cracks did not increase anymore; on the other hand, the cracking rate had limited change as the crack width increased.

\section{Numerical Simulation of Soil Moisture Movement under Evaporation}

In order to study the soil moisture movement under evaporation, a coupling numerical model of soil fluid, air, and heat was established. Then, the variation rules of soil evaporation intensity and volumetric water content during fracture development test were analyzed. 


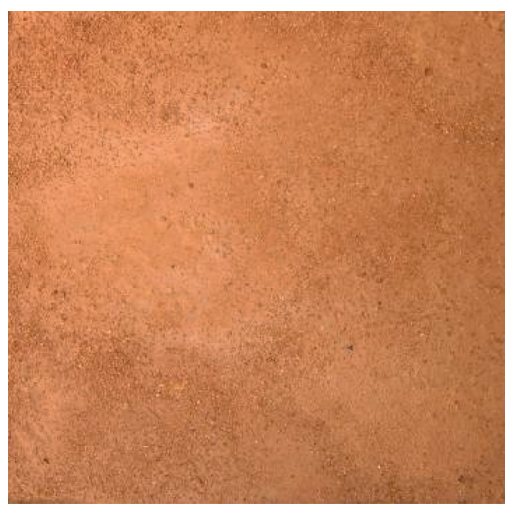

(a)

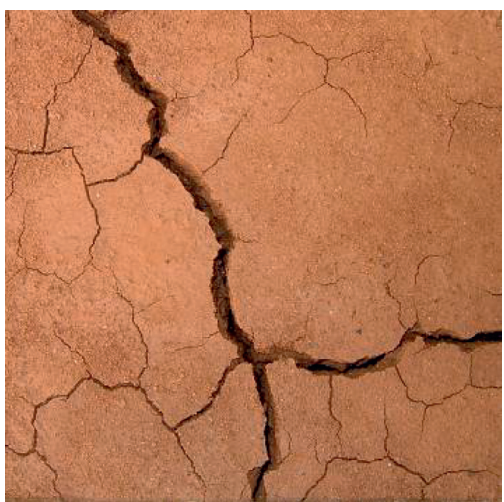

(d)

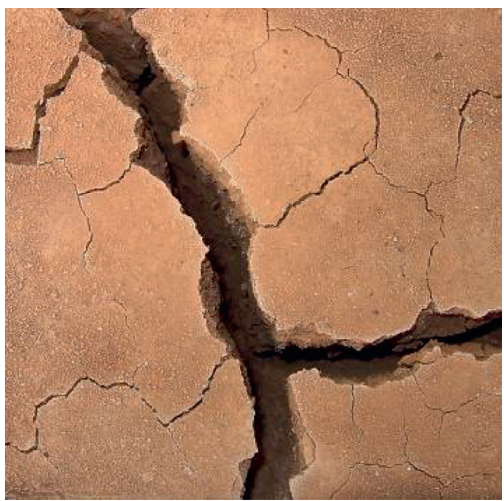

(g)



(b)

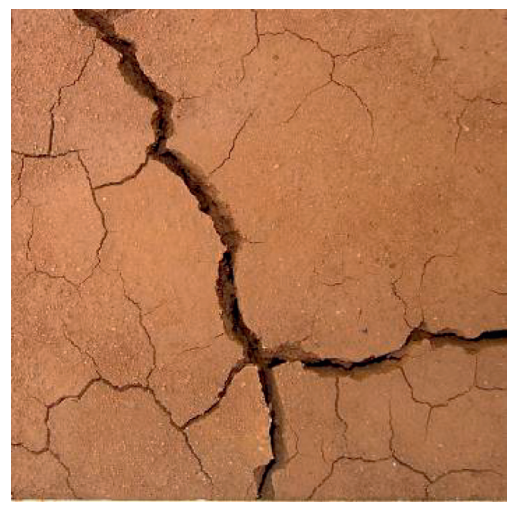

(e)

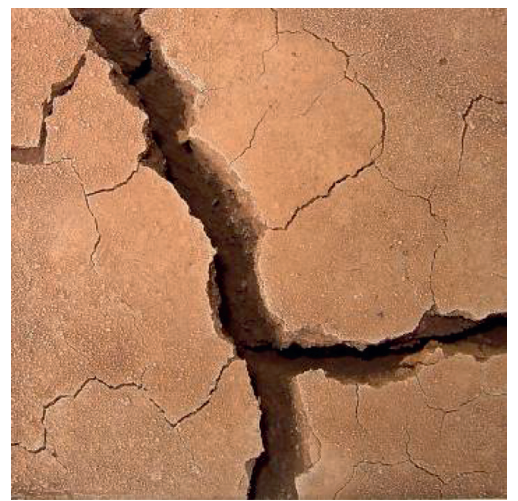

(h)

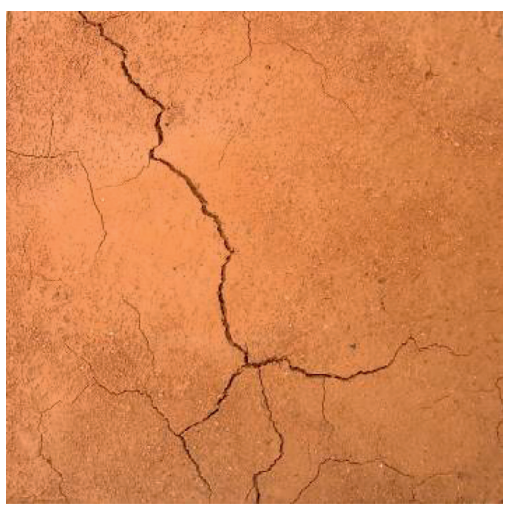

(c)

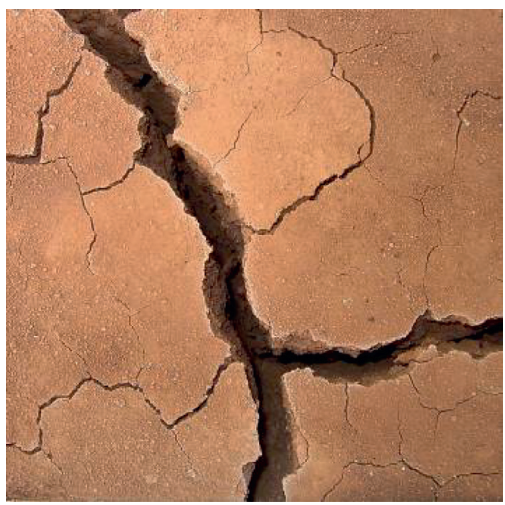

(f)

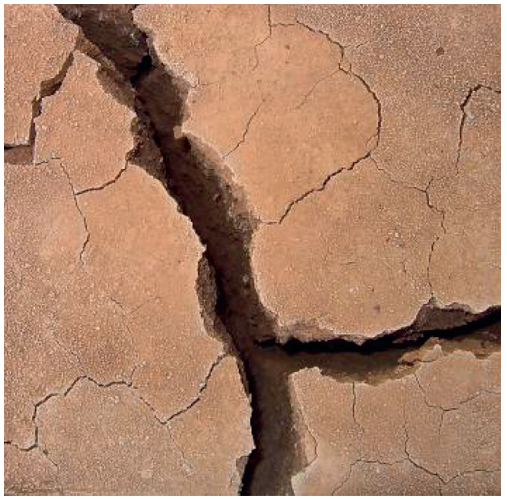

(i)

Figure 2: The process of crack development: (a) initial; (b) day 1; (c) day 4; (d) day 7; (e) day 10; (f) day 13; (g) day 16; (h) day 18; (i) final.

3.1. Coupling Numerical Model of Soil Fluid, Air, and Heat under Evaporation. Based on the water and vapor diffusion theory, Dalton [17] firstly proposed the functional relationship between the evaporation of evaporating surface, the water vapor pressure deficit, and the wind speed.

$$
E_{a}=\frac{f(w) \Delta e}{P}
$$

where $E_{a}$ is the evaporation of the free water surface; $\Delta e$ is the vapor pressure deficit; $P$ is the barometric pressure, ignoring its effect on the evaporation from water surface; and $f(w)$ is the wind speed function (a linear relationship).
Penman proposed a formula for calculating the water surface evaporation [18], based on the conservation of energy and the aerodynamic theory.

$$
E_{a}=\frac{\Delta H+\gamma E_{0}}{\Delta+\gamma}
$$

where $\gamma$ is the psychrometer constant, $H$ is the surface net radiation, $E_{0}$ is the air dry rate, and $\Delta$ is the slope of the saturated vapor pressure curve in the current average temperature.

In addition to the influence of the buried depth and supply quantity of the underground water, the actual 
TABLE 2: Soil crack geometric parameters.

\begin{tabular}{lcccccc}
\hline $\begin{array}{l}\text { Date } \\
(\mathrm{d})\end{array}$ & $\begin{array}{c}\text { Crack } \\
\text { number }\end{array}$ & \multicolumn{2}{c}{ Length $(\mathrm{mm})$} & \multicolumn{2}{c}{ Width $(\mathrm{mm})$} & Crack \\
\hline 1 & 78 & 332.071 & 4.257 & 29.707 & 0.381 & 0.004484 \\
2 & 81 & 342.257 & 4.225 & 32.401 & 0.400 & 0.004988 \\
3 & 94 & 392.258 & 4.172 & 42.245 & 0.449 & 0.008612 \\
4 & 189 & 1166.746 & 6.173 & 118.011 & 0.624 & 0.018632 \\
5 & 223 & 1723.469 & 7.728 & 201.063 & 0.901 & 0.04496 \\
6 & 218 & 1744.748 & 8.003 & 206.823 & 0.948 & 0.056352 \\
7 & 248 & 1883.845 & 7.915 & 229.436 & 0.925 & 0.058696 \\
8 & 227 & 1880.641 & 8.212 & 209.641 & 0.923 & 0.068224 \\
9 & 220 & 1898.565 & 8.475 & 205.261 & 0.933 & 0.07068 \\
10 & 216 & 1887.872 & 8.699 & 219.594 & 1.016 & 0.071628 \\
11 & 221 & 1937.768 & 8.728 & 251.492 & 1.137 & 0.083056 \\
12 & 203 & 1928.239 & 9.498 & 271.748 & 1.338 & 0.104552 \\
13 & 192 & 1983.805 & 10.332 & 264.378 & 1.376 & 0.108588 \\
14 & 193 & 1914.034 & 9.917 & 282.093 & 1.461 & 0.11072 \\
15 & 191 & 1914.888 & 10.025 & 298.899 & 1.564 & 0.121488 \\
16 & 189 & 1951.585 & 10.325 & 307.211 & 1.625 & 0.136956 \\
17 & 192 & 1948.225 & 10.147 & 313.315 & 1.631 & 0.13982 \\
18 & 194 & 1967.865 & 10.143 & 342.946 & 1.767 & 0.151456 \\
19 & 193 & 1969.143 & 10.202 & 343.812 & 1.781 & 0.152552 \\
20 & 191 & 1966.256 & 10.294 & 338.937 & 1.774 & 0.152013 \\
\hline
\end{tabular}

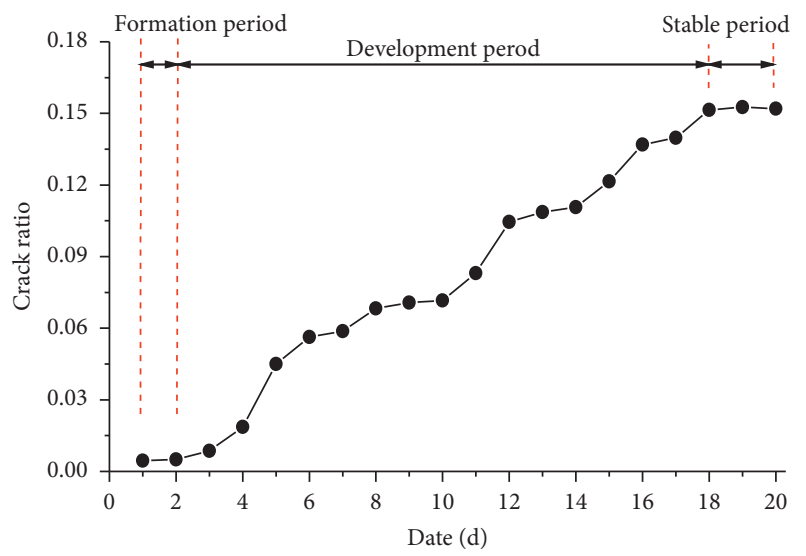

Figure 3: Crack development stages divided by crack ratio.

evaporation capacity of unsaturated soil would be primarily affected by climate factors, such as the net radiation of soil surface, humidity, temperature, and wind speed. Considering the climate factors mentioned above, Wilson [19] deduced the Penman-Wilson formula based on Penman evaporation formula to calculate the actual evaporation in the surface layer of unsaturated soil.

$$
E=\frac{\Gamma R_{n}+\eta E_{a}}{\Gamma+\eta A},
$$

where $E$ is the actual evaporation in the soil surface, $\Gamma$ is the slope of the curve between the saturated evaporation and the temperature, $R_{n}$ is net radiation of soil surface, $\eta$ is humidity coefficient, and $A$ is the reciprocal of the relative humidity of soil surface.

The osmosis of unsaturated soil reflects the nonisothermal process of the coupling between the temperature field and the humidity field. With sufficient sunshine and large temperature gradient, the movement of moisture is affected by temperature to some extent. Based on the watergas-thermal coupling migration theory raised by Philip and De Vries [20, 21], Milly proposed the motion model of flow, representing the temperature difference between the liquid state and the gas state and the influence of gravity, capillary, and adsorption capacity $[22,23]$.

$$
\begin{aligned}
& \frac{1}{\rho_{w}} \frac{\partial}{\partial x}\left(D_{v} \frac{\partial P_{v}}{\partial x}\right)+\frac{1}{\rho_{w}} \frac{\partial}{\partial y}\left(D_{v} \frac{\partial P_{v}}{\partial y}\right)+\frac{\partial}{\partial x}\left(k_{x} \frac{\partial(\psi+y)}{\partial x}\right) \\
& +\frac{\partial}{\partial y}\left(k_{y} \frac{\partial(\psi+y)}{\partial y}\right)+Q=\lambda \frac{\partial \psi}{\partial t} \\
& L_{v} \frac{\partial}{\partial x}\left(D_{v} \frac{\partial P_{v}}{\partial x}\right)+L_{v} \frac{\partial}{\partial y}\left(D_{v} \frac{\partial P_{v}}{\partial y}\right)+\frac{\partial}{\partial x}\left(\lambda_{t x} \frac{\partial T}{\partial x}\right) \\
& +\frac{\partial}{\partial y}\left(\lambda_{t y} \frac{\partial T}{\partial y}\right)+Q_{t}=\lambda_{v} \frac{\partial \psi}{\partial t}
\end{aligned}
$$

where $D_{v}$ is the steam diffusion coefficient; $\rho_{w}$ is the water density; $P_{v}$ is the water vapor pressure in soil; $\psi$ is the matric suction coefficient; $k_{x}$ and $k_{y}$ are the permeability coefficient of $x$ and $y$ direction, respectively; $Q$ is the boundary flux; $\lambda$ is the slope of indicatrix between soil and water; $Q_{t}$ is boundary heat; $L_{v}$ is latent heat of evaporation; $\lambda_{t x}$ and $\lambda_{t y}$ are the heat conductivity coefficient of soil of $x$ and $y$ direction, respectively; $T$ is the absolute temperature; $y$ is the level head; $\lambda_{v}$ is the volumetric specific heat capacity; and $t$ is the time.

The relationship between matric suction, temperature, and water vapor pressure in soil can be described by the formula below which is proposed by Edlefsen and Anderson [24].

$$
P_{v}=P_{v s}\left(e^{(-\psi \cdot w) /(\rho \cdot R \cdot T)}\right)=P_{v s} h_{\text {air }},
$$

where $w$ is the vapor molecular weight, $h_{\text {air }}$ is the relative air humidity, $R$ is the gas constant, and $P_{v s}$ is the saturated vapor pressure.

Numerical model of coupling between liquid, gas, and heat in soil could be described by simultaneous equations of formulas (4)-(6). In addition, the rule of moisture migration could be solved by the finite element numerical method and realized through the program software of Vadose.

3.2. Numerical Analysis of Evaporation Effect. As shown in Figure 4, a two-dimensional finite homogeneous soil column with the size of $1.0 \mathrm{~m} \times 0.5 \mathrm{~m}$ was established and divided into 50 units. Both sides of the model were defined as impervious boundaries, while the surface and the bottom were defined as free boundaries.

The initial state of soil was saturated state. The rainfall was set to be $0 \mathrm{~mm} / \mathrm{d}$. The meteorological data of 20 days was collected during the experiment, including the daily maximum and minimum temperature, the daily maximum and minimum humidity, and the mean value of wind speed, as shown in Figure 5. 


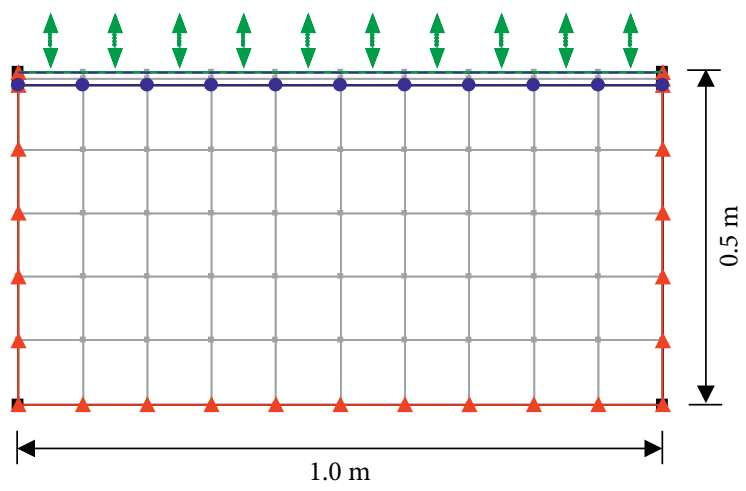

Figure 4: The numerical model of evaporation.

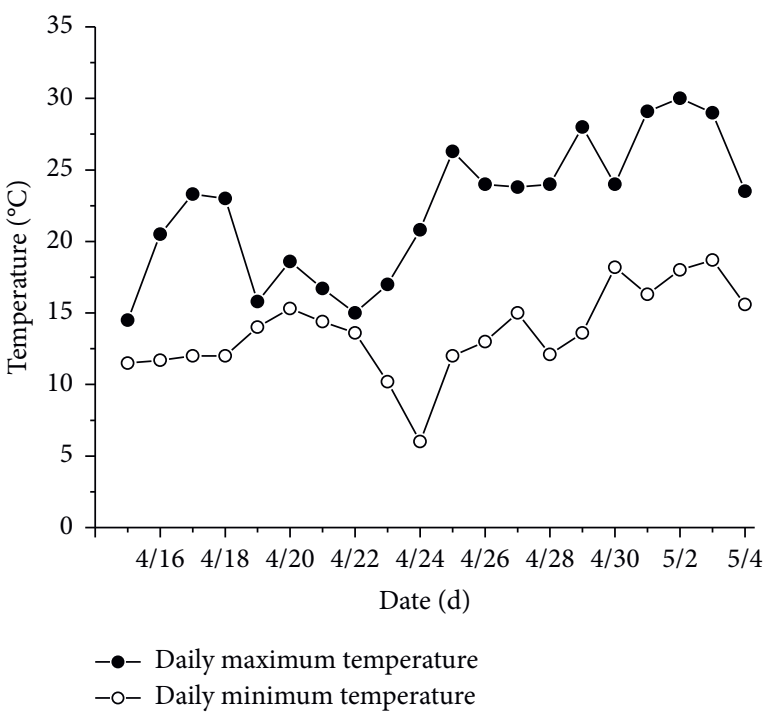

(a)

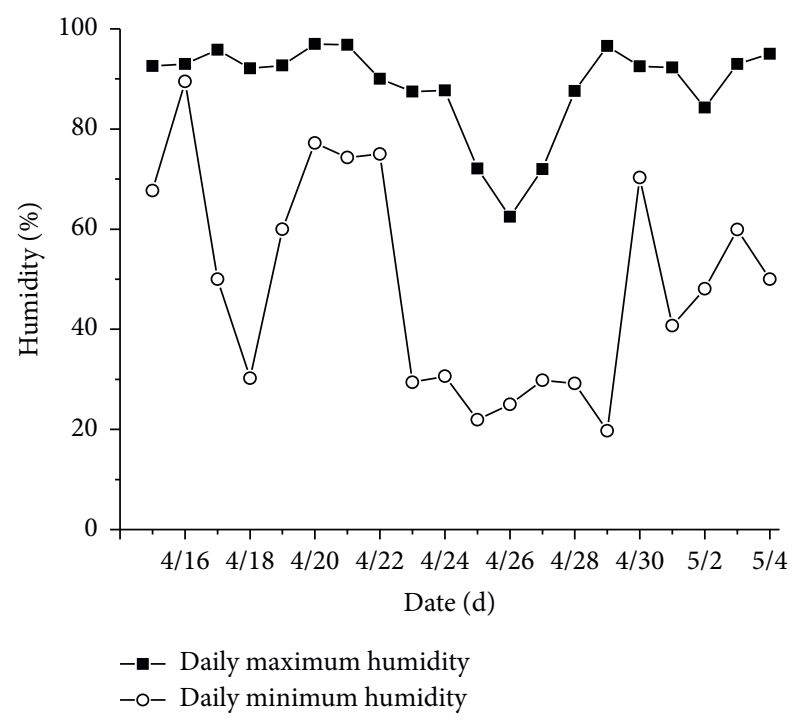

(b)

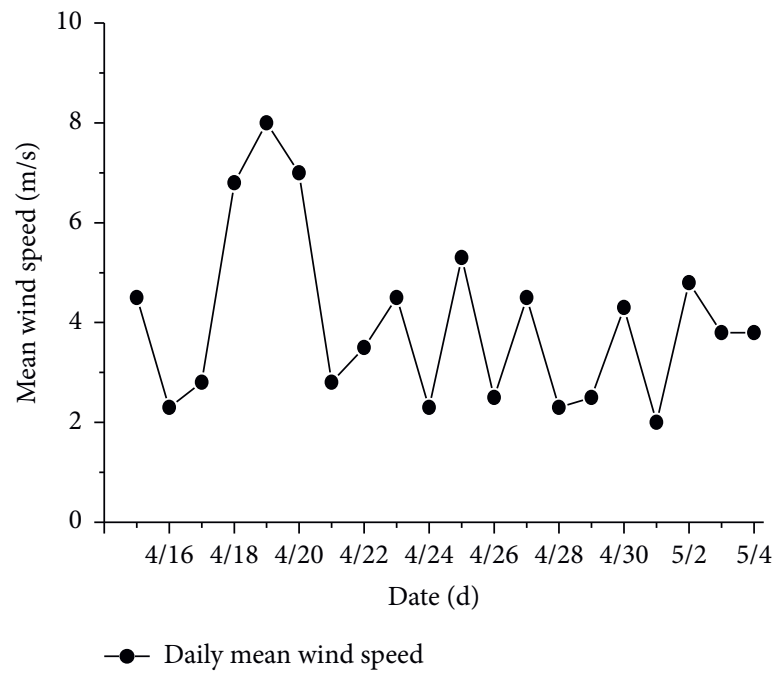

(c)

FIGURE 5: The curves of temperature, humidity, and wind speed with time: (a) temperature; (b) humidity; (c) wind speed. 
As shown in Figure 6, the permeability coefficient was calculated using the formula of Van Genuchten selected according to the soil water characteristic curve that was estimated by improved model of Kovacs (shortened to MK model [25]) via the test of soil characteristics parameters and fitted by the model of Van Genuchten [26].

The coefficient of thermal conductivity function curve was calculated with Johansen method [27], while the coefficient of thermal conductivity of natural dry soil was calculated with dry density.

$$
\lambda_{\mathrm{dry}}=\frac{0.135 r_{d}+64.7}{2700-0.947 r_{d}} \pm 20 \%,
$$

where $r_{d}$ is dry density of soil and $\lambda_{\text {dry }}$ is the coefficient of thermal conductivity of natural dry soil.

The coefficient of thermal conductivity of saturated soil was related to the composition of pore water and soil particles.

$$
\lambda_{\text {sat }}=\lambda_{s}^{1-n} \lambda_{w}^{n}
$$

where $\lambda_{\text {sat }}$ is the coefficient of thermal conductivity of saturated soil, $\lambda_{s}$ is the coefficient of thermal conductivity of soil particles, $\lambda_{w}$ is the coefficient of thermal conductivity of pore water, and $n$ is the porosity.

The coefficient of thermal conductivity of unsaturated soil was connected with the saturated and dry coefficient of thermal conductivity and the degree of saturation.

$$
\begin{aligned}
\lambda_{\text {usat }} & =\left(\lambda_{\text {sat }}-\lambda_{\mathrm{dry}}\right) \lambda_{e}+\lambda_{\mathrm{dry}}, \\
\lambda_{e} & =\log S_{r}+1.0,
\end{aligned}
$$

where $\lambda_{\text {usat }}$ is the coefficient of thermal conductivity of unsaturated soil, $S_{r}$ is the degree of saturation, and $\lambda_{\varepsilon}$ is the correction factor of $S_{r}$. Based on the formulas above, the relationship between the coefficient of thermal conductivity and volume moisture content was built as shown in Figure 7.

The volumetric heat capacity was defined as the absorption or release of energy per unit volume of soil as the temperature increased or decreased by $1^{\circ} \mathrm{C}$, which was related to the composition of three phases in soil and their heat capacities. The effect of atmosphere can be ignored. For a unit volume of soil, the heat capacity can be described as follows:

$$
\lambda_{v}=\lambda_{v s}\left(1-V_{w}\right)+\lambda_{v w} V_{w},
$$

where $\lambda_{v}$ is the volumetric heat capacity, $\lambda_{v s}$ is the volumetric heat capacity of soil particles, $\lambda_{v w}$ is the volumetric heat capacity of water, and $V_{w}$ is the volume of liquid material per unit volume of soil. The relationship between the volumetric heat capacity of cracks and the volume moisture content can then be established according to the formula above, as shown in Figure 8.

3.3. Time Characteristics of Evaporation. The curve of volume moisture content on soil surface and soil evaporation intensity change over time is shown in Figures 9 and 10. The results implied that the soil surface evaporation process can be divided into three stages on the basis of the function of evaporation capacity and soil water supply capacity and the characteristics and rules of soil surface evaporation.

At the beginning of evaporation, the hydraulic conductivity decreased due to fast decline of the soil surface moisture content. However, due to the complement role of the increased suction gradient, the soil surface evaporation intensity was maintained at a stable level rather than declined with the drop of moisture content, roughly the same as free water surface evaporation intensity, which was the stable evaporation stage. In the early stage of the evaporation process, the migration of water caused by moisture movement and gaseous water movement was so weak that it could be ignored.

In the second stage of evaporation, the soil moisture content declined below the critical moisture content. When the soil moisture content was higher than the air-dried moisture content, the surface soil moisture stress decreased slowly approaching the saturated moisture stress. With the decline of water circulation, the gas flow increased gradually. The movement of water is carried out by the coexistence of liquid flow and gas flow. Therefore, the surface moisture flux was the important part of evaporation. Since the water carrying capacity of soil became weaker and weaker, the surface was unable to replenish evaporated water to decrease the surface moisture content. Then, the matrix suction entered into the phase of rapid growth, and the evaporation reduced consequently.

When the surface moisture content was below the airdried moisture content, the water carrying capacity of soil became too weak to supply the evaporated water, which led to dry-soil formation on surface. The evaporation intensity changed slowly and steadily, depending on the control capacity of dry-soil moisture diffusion and dry-soil layer depth.

\section{Discussion}

The development process of cracks is a dynamic process affected by climate conditions. Under the effect of evaporation, the soil continuously lose water and shrinks, thus forming cracks. Crack width is an important parameter that characterizes cracking development. By establishing the relationship between the water content and the crack width, the dynamic prediction of crack development under soil evaporation can be realized.

As presented in Figure 11, the average crack width changed as the moisture content decreased in soil. It shows that after a sharp decline, the moisture content stayed steady at $6 \%$ eventually. After a short cracking process, the crack width increased quickly and gradually became stable in the end. The development of crack width consisted of 3 stages: slow development, fast development, and stable development. At the beginning, the desiccation crack was generated because of the existence of weakness somewhere on the surface as well as a larger shrinkage rate compared to the lower layer. The reason why the crack developed slowly at the start time was that the sample that stayed in a relatively high level of moisture content and contacted the external environment with only the surface underwent overall contraction. With the 


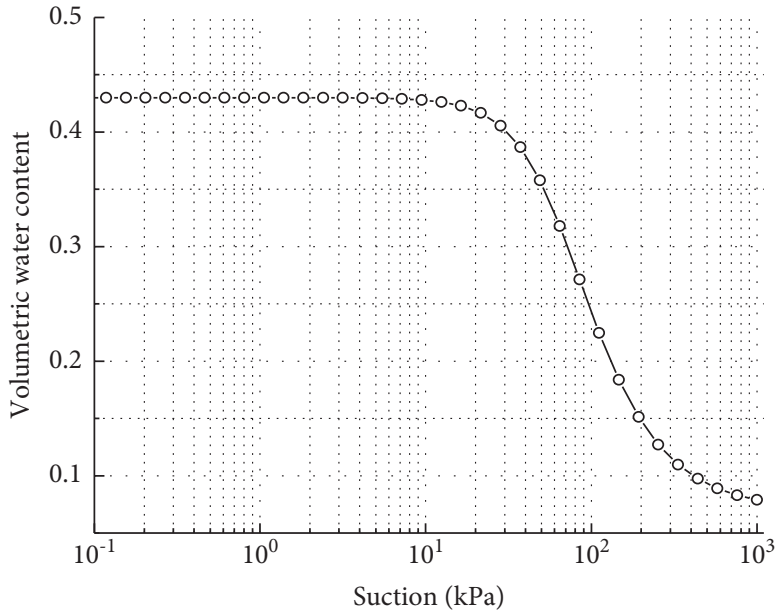

(a)

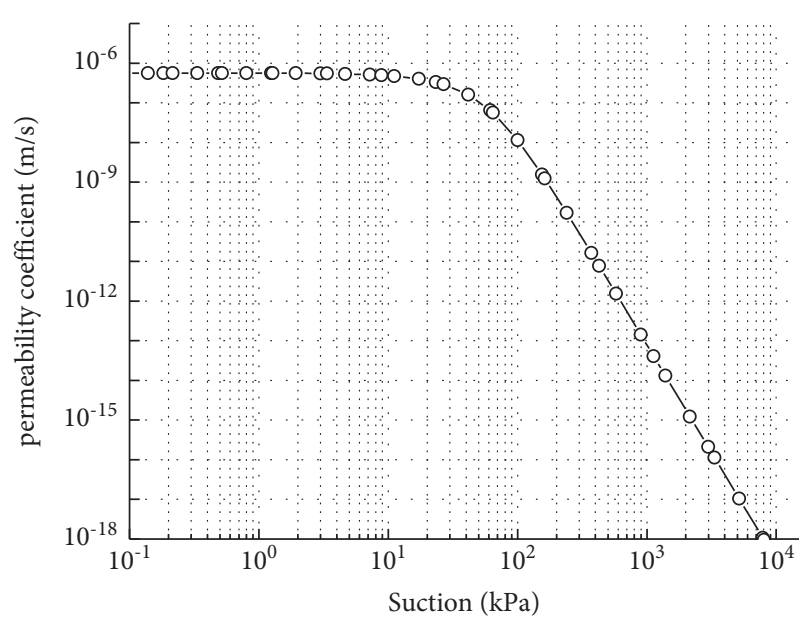

(b)

FIgURE 6: Hydraulic parameters of unsaturated soil: (a) soil water characteristic curve; (b) permeability function.

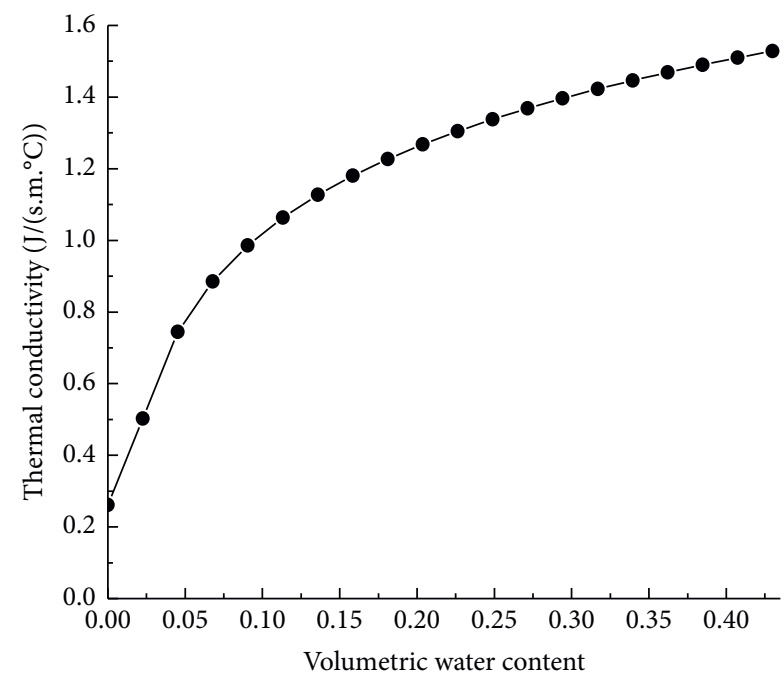

FIgURE 7: Thermal conductivity curve.

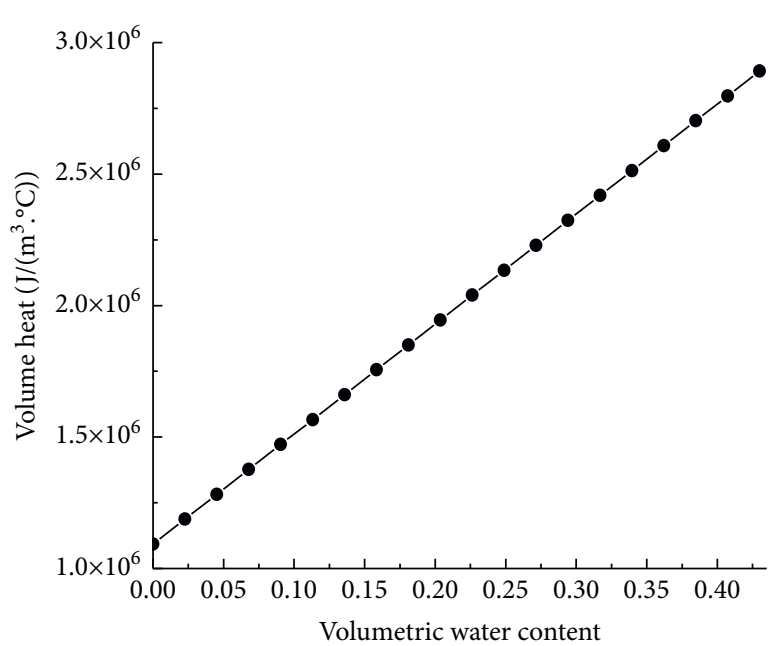

FIgURE 8: Volume heat curve.

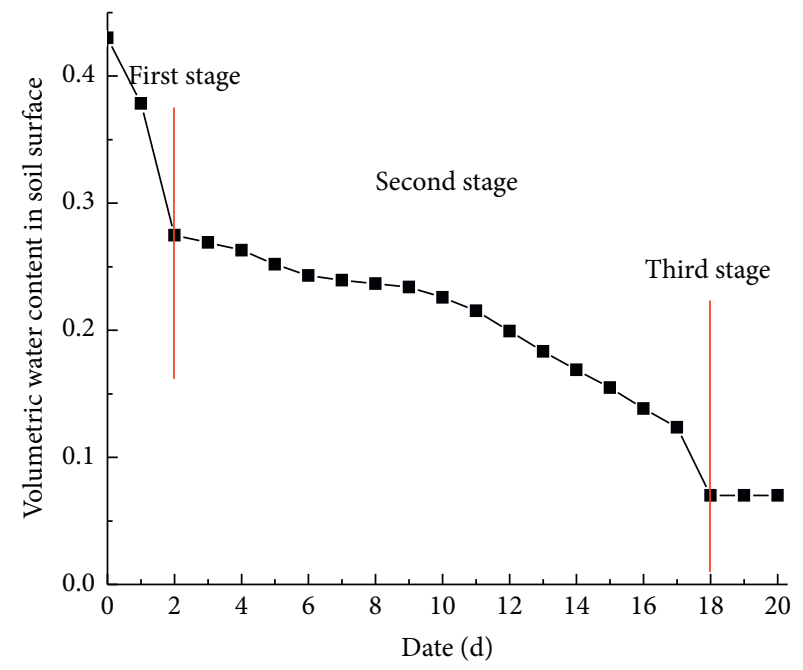

FIGURE 9: The change of volumetric water content on soil surface.

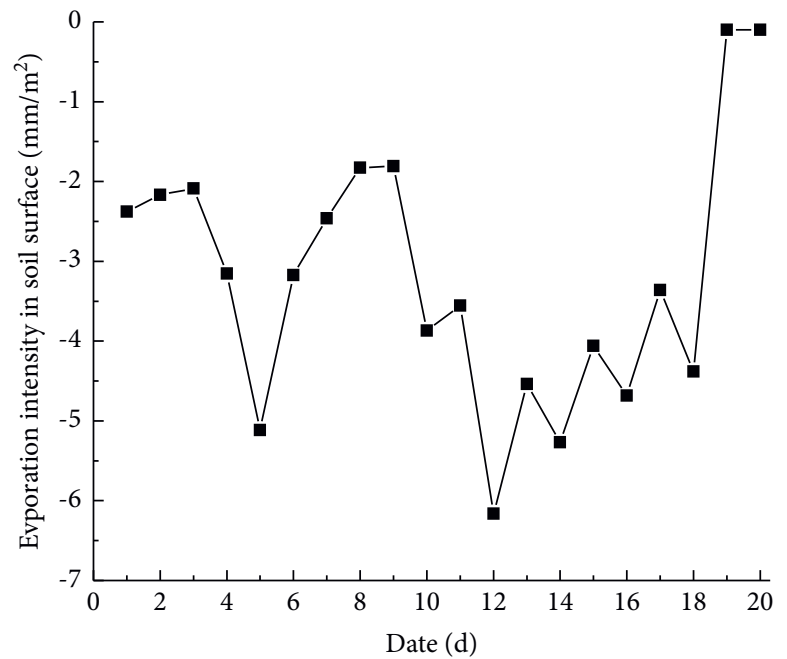

FIGURE 10: The change of evaporation intensity on soil surface. 


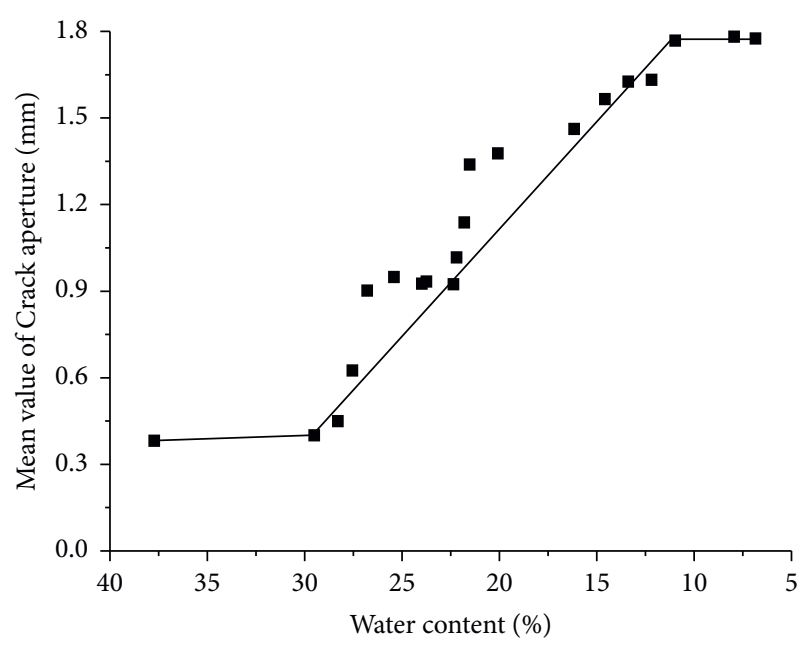

Figure 11: The relationship between mean value of crack aperture and water content.

generation of crack, the contact area between crack and external environment expanded quickly, leading to the increase of filtration rate and a sharp movement of crack. When the crack expanded to a certain degree, soil on both sides of the crack performed a stronger limitation with the increase of crack depth. Although the moisture content of soil declined, the matric suction was no longer the main factor controlling the soil properties. The slow development process indicated that the crack reached a stable stage.

For the crack in natural conditions, there was an obvious function relation between the moisture content and the crack width as described in Figure 10. Based on the time effect of soil evaporation, the crack width change with moisture content could be described quantitatively as follows:

$$
\begin{cases}b=b_{1}, & \theta \leq \theta_{k}, \\ b=m \theta_{k}+n, & \theta_{c}<\theta<\theta_{k}, \\ b=b_{3}, & \theta \leq \theta_{c},\end{cases}
$$

where $b_{1}$ is the width of initial cracking soil, $\theta_{k}$ is the boundary of moisture content between the first and second stage of evaporation, $\theta_{c}$ is the air-dried moisture content, $m$ and $n$ are fitting parameters, and $b_{3}$ is the width of ultimate cracking soil. According to the calculation, the values of $m$ and $n$ are $-0.077 \mathrm{~mm}$ and $2.617 \mathrm{~mm}$, respectively. In the stable evaporation stage, the water content decreases from $29 \%$ to $11 \%$, and the crack width increases from $0.39 \mathrm{~mm}$ to $1.77 \mathrm{~mm}$.

\section{Summary and Conclusions}

In this paper, experimental and numerical analysis of soil cracking characteristics under evaporation are carried out. The following conclusions are drawn:

(1) Soil crack development test was carried out to observe the occurrence and development of cracks in soil samples during evaporation. By analyzing the geometric characteristic values of cracks in each stage, the development law of cracking is described quantitatively. The results show that the process of soil crack development under evaporation can be divided into three stages: crack formation stage, crack development stage, and crack stability stage.

(2) The law of soil water transport under evaporation was analyzed through numerical simulation of soil evaporation process in atmospheric environment. The evaporation process of soil surface can be divided into three stages. In the early evaporation stage which is called formation stage, the evaporation intensity of surface soil was maintained at a stable value instead of decreasing with the moisture content. In the second phase, the surface soil moisture decreased while evaporation was also reduced. In the third stage, evaporation of surface soil happened inside, and the changing rate of the evaporation intensity was generally very slow and steady.

(3) The functional relationship between the soil moisture content and the crack width under evaporation was established. The dynamic prediction of crack development was realized. The results showed that the water content decreased from $29 \%$ to $11 \%$, while the crack width increased from $0.38 \mathrm{~mm}$ to $1.77 \mathrm{~mm}$ in the stable evaporation stage.

\section{Data Availability}

The data used to support the findings of this study are available from the corresponding author upon request.

\section{Conflicts of Interest}

The authors declare that they have no conflicts of interest.

\section{Acknowledgments}

This work was supported by the Fundamental Research Funds for the Central Universities (Grant no. 2018B04914), Central Public-Interest Scientific Institution Basal Research Fund grant funded by the Chinese government (Grant no. Y32003), and Transportation Science and Technology Project of Jiangsu Province, "Study on Key Technologies of Highway Protection by Slope Construction First Method."

\section{References}

[1] L. Yang and E. Liu, "Numerical analysis of the effects of crack characteristics on the stress and deformation of unsaturated soil slopes," Water, vol. 12, no. 1, p. 194, 2020.

[2] Y. Wang, D. Feng, and C. W. W. Ng, "Modeling the 3D crack network and anisotropic permeability of saturated cracked soil," Computers and Geotechnics, vol. 52, pp. 63-70, 2013.

[3] Q. Cheng, C. S. Tang, D. Xu, H. Zeng, and B. Shi, "Water infiltration in a cracked soil considering effect of dryingwetting cycles," Journal of Hydrology, vol. 593, no. 7566, 2020.

[4] C. J. Miller, J. Mi, and N. Yesilleer, "Experimental analysis of desiccation crack propagation in clay liners," Journal of the American Water Resources Association, vol. 34, no. 3, pp. 153-163, 1998. 
[5] C. Tang, B. Shi, C. Liu, L. Zhao, and B. Wang, "Influencing factors of geometrical structure of surface shrinkage cracks in clayey soils," Engineering Geology, vol. 101, no. 3-4, pp. 204-217, 2008.

[6] C. Tang, Y. Cui, A. M. Tang, and B. Si, "Experiment evidence on the temperature dependence of desiccation cracking behavior of clayey soils," Engineering Geology, vol. 114, no. 3-4, pp. 261-266, 2010.

[7] C. Tang, Y. Cui, A. M. Tang, and B. Si, "Shrinkage and desiccation cracking process of expansive soil and its temperature-dependent behavior," Chinese Journal of Geotechnical Engineering, vol. 34, no. 12, pp. 2181-2187, 2012.

[8] G. Liu, Y. Chen, X. Zeng, and G. Zhang, "Effects of ambient air humidity and temperature on crack development of compacted expansive soils," Chinese Journal of Geotechnical Engineering, vol. 42, no. 2, pp. 259-268, 2020.

[9] C. Wu, Y. Wang, D. Feng, and Y. Zhou, "Experimental study on the coupled behavior of dynamic cracking and moistureheat evolution of a clay under evaporation," Bulletin of Engineering Geology and the Environment, vol. 80, no. 6, pp. 4943-4955, 2021.

[10] F. H. Lee, K. W. Lo, and S. L. Lee, "Tension crack development in soils," Journal of Geotechnical Engineering, vol. 114, no. 8, pp. 915-929, 1988.

[11] J. Bronswijk, "Drying, cracking, and subsidence of a clay soil in a lysimeter," Soil Science, vol. 152, pp. 92-99, 1991.

[12] P. H. Morris, J. Graham, and D. J. Williams, "Cracking in drying soils," Canadian Geotechnical Journal, vol. 29, no. 2, pp. 263-277, 1992.

[13] J. M. Konrad and R. Ayad, "Desiccation of a sensitive clay: field experimental observations," Canadian Geotechnical Journal, vol. 34, pp. 850-858, 1997.

[14] J.-M. Konrad and R. Ayad, "A idealized framework for the analysis of cohesive soils undergoing desiccation," Canadian Geotechnical Journal, vol. 34, no. 4, pp. 477-488, 1997.

[15] J.-H. Wu, J.-P. Yuan, and C. W. W. Ng, "Theoretical and experimental study of initial cracking mechanism of an expansive soil due to moisture-change," Journal of Central South University, vol. 19, no. 5, pp. 1437-1446, 2012.

[16] J. H. Li and L. M. Zhang, "Geometric parameters and REV of a crack network in soil," Computers and Geotechnics, vol. 37, no. 4, pp. 466-475, 2010.

[17] J. Dalton, "Experimental essays on the constitution of mixed gases; on the force of steam or vapor from water and other liquids in different temperatures, both in a torricellian vacuum and in air; on evaporation and on the expansion of gases by heat," Memoirs and Proceedings of the Manchester Literary and Philosophical Society, vol. 5, pp. 535-602, 1802.

[18] H. L. Penman, "Natural evapotranspiration from open water, bare soil and grass," Proceedings of the Royal Society of London, vol. 193, pp. 120-146, 1948.

[19] G. W. Wilson, D. G. Fredlund, and S. L. Barbour, "Coupled soil-atmosphere modelling for soil evaporation," Canadian Geotechnical Journal, vol. 31, no. 2, pp. 151-161, 1994.

[20] J. R. Philip and D. A. De Vries, "Moisture movement in porous materials under temperature gradients," Transactions-American Geophysical Union, vol. 38, no. 2, pp. 222-232, 1957.

[21] D. A. De Vries, "Simultaneous transfer of heat and moisture in porous media," Transactions-American Geophysical Union, vol. 39, no. 5, p. 909, 1958.

[22] P. Milly, "Moisture and heat transport in hysteretic, inhomogeneous porous media a matric head-based formulation and a numerical model," Water Resource Research, vol. 18, pp. 489-498, 1982.

[23] P. C. D. Milly, "A linear analysis of thermal effects on evaporation from soil," Water Resources Research, vol. 20, no. 8, pp. 1075-1085, 1984.

[24] N. E. Edlefsen and A. B. C. Anderson, "Thermodynamics of soil moisture," Hilgardia, vol. 15, no. 2, pp. 31-298, 1943.

[25] P. J. Kamann, R. W. Ritzi, D. F. Dominic, and C. M. Conrad, "Porosity and permeability in sediment mixtures," Ground Water, vol. 45, no. 4, pp. 429-438, 2010.

[26] M. T. van Genuchten, "A closed-form equation for predicting the hydraulic conductivity of unsaturated soils," Soil Science Society of America Journal, vol. 44, no. 5, pp. 892-898, 1980.

[27] O. Johansen, Thermal Conductivity of Soils, University of Trondheim, Trondheim, Norway, 1975. 